\title{
Peculiarities of the Design of Vocational Training Content of the Environmental Engineer in the Sixth Technological Paradigm
}

\author{
Artemiy Kozachek \\ Ph.D., Associate Professor, Executive Director, Association "United University of V.I. Vernadsky" \\ artem_kozachek@mail.ru
}

\section{Doi:10.5901/mjss.2015.v6n6s5p205}

\section{Abstract}

\begin{abstract}
The article considers the problem of unavailability of the modern system of design for vocational training content of the environmental engineer to the requirements of the upcoming in the near future sixth technological paradigm. The literature review showed the lack of scientific and methodological proposals to solve this problem, the objective reason of which was the cause of the inertia of the system of engineering and environmental education which is focused on the fifth and fourth technological paradigms. The author of the article seeks to identify common features of designing for vocational training content of the environmental engineer in the new technological paradigm. An innovative approach is suggested in the framework of which the decomposition of the definition of the sixth technological paradigm into components, then the analysis of each of these components with the aim to identify potential environmental problems of the future and predict the expected ecological engineering methods for solving of such problems is done. The results of such decomposition and analysis are synthesized to highlight relevant features of designing for vocational training content of the environmental engineer in the future. This approach has been tested by the author on the example of one of the key technologies of the sixth technological paradigm - nanotechnology, resulted in identifying a new type of contaminants in the sphere of nanotechnology use, namely nanoparticles; their possible negative impact on human health is also considered. At the same time the author made an attempt to predict the emergence and nanotechnological solutions in the field of environmental protection, which at the level of the microcosm will allow developing robotic systems of fighting with nanopollution. The obtained results allowed to identify common features that must be taken into account in the vocational training of the environmental engineer for the period up to the middle of the XXI century as well as to propose appropriate practical recommendations.
\end{abstract}

Keywords: design for the vocational training content, environmental engineer, the sixth technological paradigm.

\section{Introduction and Description of the Problem}

At present, in the engineering and environmental activities, we should see a whole new group of factors that were not previously taken into account in a professional environmental pedagogy:

1) emergence of a new group of man-made environmental impact of the technosphere on the planet;

2) globalization of the world economy that may affect the state of the technosphere;

3) all increasing reaction of the environment, response to global technological influences.

The first of above-mentioned signs is characterized by the fact that up to date, the activities of the technosphere, associated with the extraction of natural resources and manufacturing of products have so much impact on the environment that we suggest speaking about the emergence of a new group of effects - man-made environmental impacts, which are distinct from the abiotic, biotic and anthropogenic environmental factors that were distinguished before. We propose to outline three main types of man-made environmental impacts, which can be correlated with global environmental issues, namely the seizure and the use (consumption) of natural resources by man, man-made infringement of environmental components, the transfer of technological waste into the environment and its pollution.

Technosphere in its development has passed and goes through various stages of technogenesis. These stages are called technological structure (Perez, 2002; Glazyev \& Kharitonov, 2009). S.Y. Glazyev believes that "the technological paradigm is a holistic and sustainable education, within which a closed cycle takes place starting with the extraction and obtaining primary resources and ending with the release of a set of final products, appropriate to the type of public consumption. The complex of basic totality of technically conjugated production constitutes the nucleus of the technological paradigm. Technological innovations that define the formation of the nucleus of the technological paradigm are called a key factor. The industries that intensively use a key factor and play a leading role in the expansion of a new technological paradigm are bearing branches» (Glazyev \& Kharitonov, 2009). 
Every technological system has a life cycle of about the same time length, which is 40 to 60 years. At present scientists distinguish a different number of technological paradigms, but in all well-known researches the figures vary slightly from five to seven. We accept the opinion of the scientific school under the leadership of S.Y. Glazyev, according to which by now five technological paradigms have been distinguished and the sixth technological one has just started.

So, according to scientists, in the first quarter of the XXI century the sixth technological paradigm will be in the growth phase. According to Academician S.Y. Glazyev, this structure will be characterized by the supremacy of nanotechnology and molecular biology that in the period up to 2050 must change the life on the planet and the world economy (Glazyev \& Kharitonov, 2009).

Summarizing the findings of various authors, we propose to consider that the sixth-technological paradigm is a mode of new materials and technologies of the treatment of materials. New materials we propose to consider:

- Nanomaterials obtained with the help of nanotechnology;

- Biomaterials obtained using molecular biology techniques, biotechnology and genetic engineering;

- Artificially created composite materials (similar in composition and properties and other parameters to natural materials) obtained by the methods of industrial chemistry, physics and biology;

- Radio-electro-materials that will contribute to provide even more rapidly development of informational technologies, the strengthening of global information space.

Application of the above-mentioned new materials will allow to start a new round of scientific and technical progress, in the framework of which innovative materials will increase the efficiency of work of the technological equipment, improve taste and other useful properties of the products, solving the problem of shortage of food for a growing world population, improving maintainability, survivability and improve self-rehabilitating ability of different machines, clothes, ranging from the space sector to the urban communes.

In connection with the above said, in our opinion, there are certain problems in design of vocational training content of environmental engineering, in perspective of activities of the environmental engineer, as today's young (17 to 22 years old) students will have become mature experts by the time of active implementation of the sixth technological paradigm in the planetary world economy. However, at present the environment almost does not reflect the requirements of the sixth technological paradigm. The financial and economic crisis, the fall and the strong volatility in the stock and commodity markets since 2014, especially in 2015 , a change in the political situation at the same time, the creation or a clearer identification of global military, economic and political coalitions by 2015 are related, according to economists, to the beginning of a new technological paradigm, and they have now almost no reflection in the content of engineering and environmental training.

\section{Review of the Existing Approaches}

It should be noted that at this point in the Russian and foreign literature there are proposals to modernize the contents of environmental engineer training, but in the framework of the fourth and fifth technological paradigm. Here it may be noted the work of many scientists such as (Knight, 1987; Cawsey, 1996; Pudlowski \& Nguyen, 1999 et al.). However, most of such works have become obsolete. The objective reason, in our opinion, here lies in the fact that the sixth technological paradigm came only in 2010 , or still it is the time of its occurrence. Taking into account the inertia of the education system, in principle, in any country, it is clear that scientists-educators of environmental profile are only beginning to comprehend this problem. However, it should be noted that now there is a number of researches on cognitive technologies and possible application in the future pedagogy, however, it is only a very narrow side of engineering and environmental education, and such works do not provide a comprehensive coverage of the whole problem of training is the environmental engineer in the coming future.

Accordingly, graduates of ecological specialties and spheres being a student are undergoing ethical and psychological impact of the existing contradiction between the content of education and the essence of the changes in the world, and when graduating, they cannot be considered to have sufficient qualifications, as these competencies do not meet the requirements of the coming sixth technological paradigm and modern shocks in the economy that are associated with its first phase.

These contradictions do not allow at the moment to create a fully integrated understanding of the content of modern environmental science. 


\section{The Suggested Approach and Its Stages}

To solve this problem we propose the approach that includes an analysis of changes in the object of ecology, taking into account external factors of global economy and the world of technologies in the framework of the upcoming sixth technological paradigm.

Our approach is to implement two main stages. In the first stage we will implement of decomposition of the definition of the sixth technological paradigm that will allow us to highlight its main components. Here we conduct a meaningful analysis of the selected components to determine the characteristics of the future impact of the technosphere to the environment in the framework of the sixth technological paradigm and, at the same time, in order to anticipate possible new engineering and environmental solutions in the coming period.

Finally, in the second stage on the result basis of the first two stages, we propose to define the general features of the design of vocational environmental training content to ensure that the competence of the environmental engineer graduating the university at the beginning of the sixth technological paradigm corresponds to the new requirements of this paradigm.

\section{Factors of Content of Vocational Training of the Environmental Engineer in the Era of the Sixth Technological Paradigm}

Conducting the decomposition of the definition of the sixth technological order, proposed by scientists, we offer the following to allocate its basic components:

1) technological innovations as a key technological paradigm;

2) a set of basic sets of technologically conjugated industries, which form the nucleus of a technological paradigm and determine the nature and characteristics of technological innovation;

3) supporting industries that implement technologically conjugated production, applying technological innovations.

As it can be seen from this definition, the beginning of the technological paradigm forms technological innovation (innovation). At the same time from the general theory of the techno sphere (Fogger \& Mines, 1991) it is known what technological innovation defines the degree of negative / positive effects of the technosphere on the environment and, at the same time, this technological innovation forms the new approaches and engineering solutions for the protection of the environment during the new technological paradigm.

For example, innovations in nanotechnology have led to the appearance of products, materials with completely new, previously unknown properties, which are increasingly applicable in various industries. Thus, based on the understanding of the functioning of technosphere it is possible to say that at the end of the life cycle of use and consumption data nanomaterials or their processed products are transferred as waste into the environment. In other words, we can talk about new kinds of negative, and still not fully examined impact on the environment.

Thus, we believe that in the future these materials may become a source of the so-called nanopollution. There is already first information about their appearance and impact on human health and the natural organisms.

Thus, German scientists have conducted studies that have shown that contact of nanoparticles with the human body is related to the frequency of heart attacks and concentration of nanoparticles in the atmosphere, there is a dependence of cardiac arrhythmias of high concentration of nanoparticles, the risk of inflammation in the lung tissue causes problems with mediators, increases blood clotting and rapid clogging of blood vessels (Shupenburg, 2008).

Researchers of the Institute of Occupational Medicine of the Academy of Medical Sciences of Ukraine determined that the powders of nanoparticles of highly dispersed silica, intra-tracheally injected into laboratory rats during three months caused a decrease in relative weight of adrenal glands", which, according to scientists, affected the stress resistance in rats, as well as changes in the lungs, reflected in "entire vascular hyperemia ... desquamation of bronchial epithelial cells in their lumen, as well as patchy alveolar emphysematous expansion gaps with thinning alveolar septum. At the same time, these authors according to the results of their research ultimately conclude that "inhalation of nanoparticles of highly superfine amorphous silica into the body of people working in the conditions of their production, is dangerous for health" (Didenko \& Stezhka, 2009).

Researchers from the University of Calgary in the United States proved the effect of nanoparticles that are in the blood circulatio, on the development of chicken embryos (Clancy et al., 2010).

According to A.A. Anciferova, the scientist of "Kurchatov Institute", active use of nanotechnology in industry and domestic spheres of life of people can cause positive results and negative consequences. Among the effects that have an adverse toxic effect on the organism, A.A. Anciferova includes, for example, the following (Anciferova, 2015): 
- behavioral change of mice receiving during the month nano-preparation of silver (mice fail to respond to bright light, their behavior is activated);

- titanium dioxide nanoparticles which are a part of sunscreens, through the implementation of so-called phototoxic effect can cause skin cancer;

- nanoparticles of organic origin, such as fullerenes, when getting into the body cause the body's response in the form of appearance of antibodies, act as an antigen and can cause a variety of inflammatory processes.

We propose to consider that a possible way to reduce the environmental risks at the stage of the sixth technological paradigm should be methods based on the same technology of the micro world, which for this way of life will be actively developed and applied. To such technologies we refer technologies of environmental nano engineering when produced with the use of such technologies nanorobots-replicators having in the basis of their structure both nanobiological and chemical elements will by the command of a man or a machine destroy the sources of pollution, polluting substances and pestholes.

Hence, it is necessary to study them and, in the future, develop a complex of measures to combat this new type of man-made impact. At the same time, nanotechnologies enable to improve environmental technology. For example, there are various water filters using nano sorbents allowing, according to its developers, to increase the effectiveness of water treatment to levels of medical and food safety while reducing the total cost of such treatment. This situation requires environmental engineer to have new competencies that will enable him to exploit effectively such innovative equipment.

As a result, we believe that technological innovations actually should become the basis to build in the framework of the next technological paradigm a new registry of didactic units in the vocational training content of the environmental engineer.

Scientists that are concerned with the problems of the technological paradigm, identify a number of manufacturing technologies that will form the basis of the sixth technological paradigm.

According to the academician S.Y. Glazyev as the technologies of the sixth technological paradigm it is necessary to note "nanoelectronics, molecular and nanophotonics, nanomaterials and nanostructured coatings, optical nanomaterials, nanoheterogenous system, nanobiotechnology, nanosystems engineering, nanoequipment ... biotechnology, based on advances in molecular biology and genetic engineering, nanotechnology, artificial intelligence systems, global information networks and integrated high-speed transport systems» (Glazyev \& Kharitonov, 2009), where nanotechnology is considered to be a key factor of the technological paradigm.

These lists are generally similar, and give a visible picture of the future registry disciplines as didactic units of the vocational training content of the environmental engineer.

The nucleus of the technological paradigm forms a basic complex of technologically conjugated industries, which are built on the results of the development, commercialization and real technological innovation in enterprisesconsumers. The production is impossible without consumption, making it an indissoluble unity, since, on the one hand, the production creates raw materials and materials for the sphere of consumption, on the other hand, the production itself is a consumer of natural resources (Semyonov, 2003). It can be concluded that the complex of basic sets of technologically conjugated industries in the new technological paradigm in its development is accompanied by a simultaneous and similarly directed changes in the sphere of consumption, when consumers-innovators start to use new technologies, and then gradually in the life cycle of production and sales, such new technology progressively accept a growing number of other groups of consumers, eventually becoming the standard in the world of consumption.

Besides, in the structure of the interaction of the technosphere to the environment we are consider spheres of production and consumption as a major source of complex settled anthropogenic impact on natural objects.

We believe that technological innovations, as mentioned above, define new types of man-made positive / negative impact on the environment and new challenging environmental technologies. At the same time a considered here complex of technologically conjugated industries simultaneously with the changes in consumption enable to detect new types of anthropogenic effects, which include three of the above-said. In addition, these types of anthropogenic impacts are defined not only in terms of their enumeration, but also in terms of their essence. In other words, knowing the peculiarities of the reformation of industrial and consumer spheres, we can understand the content of new types of anthropogenic impact.

For example, innovations in nanotechnology, defining a new kind of nanopollution of the environment enabling to analyze the nature and structure of the newly established production of nanoproducts and consumption markets of corresponding production, work and services. Such analysis can be carried out by the well-known methods of economy, organization theory, business planning, etc., as well as by the methods of analysis of technological production, technology assessment and evaluation of the effectiveness of the technological structure of production. Built structure of 
production and consumption of nanoproducts gives us information about the useb resources (natural, raw materials, etc.) and formed during the process of production and consumption contaminants (including their chemical formulas, physical properties, the possible toxic characteristics and others.). At the same time with the help of a variety of environmental methods of assessment of industrial impact on the environment, methods of environmental audit and control, we can identify a list of relevant anthropogenic violations of environmental components, such as, peculiarities, the depth of soil disturbance on the territory of the construction and operation of the studied production, features and quantitative indicators of depletion of underground water resources in the territory, etc.

As a result, we are able to form an ecological passport of a studied innovative production, where specific quantitative characteristics of new types of technological impacts of the production will be outlined. How will this affect the design of the vocational training content of the environmental engineer? This approach enables to single out new professional competencies of the environmental engineer and corresponding spheres of environmental training in specific disciplines of the previously formed registry. There is also an opportunity, for example, to make the filling of a content of environmental disciplines with new types of practical problems, laboratory work of analytical and design nature.

Now we need to analyze the term "supporting industries that implement technologically conjugated production, applying technological innovations." The economy sector is a set of companies that produce similar products for the same type of technology (Rayzberg et. al., 2007). From this definition, we can say that the supporting industry in the new technological paradigm is a set of new enterprises of the new formation, which performed a basic set of technologically conjugated industries, using the same type of technological innovation of the technological paradigm.

There are the following supporting industries of the sixth technological paradigm (Glazyev \& Kharitonov, 2009):

- Electronic, nuclear and electrical industries;

- Information and communication sector;

- Machine tools, shipbuilding, automotive and instrumentation industries;

- Pharmaceutical industry;

- Solar energy;

- Aerospace industry;

- Aircraft industry;

- Cellular Medicine;

- Seed industry;

- Building;

- Chemical and metallurgical complex.

Definition of supporting branches of the sixth technological paradigm enables to create a system of forecasting possible geography and intensity of anthropogenic impact of such industries on the future. Thus, it is possible to determine the prospects and directions of development of engineering and environmental industry in view of its alleged cooperation with supporting industries. At the same time, features of the interaction of the system of vocational engineering and environmental training with employers, as the selection of innovative productions of the new technological paradigm and the corresponding types of man-made impact with specific quantitative indicators for a certain region enable to detect new economy clusters in the region, with which enterprises agreements on cooperation in training and employment of graduates, agreements on the environmental assessment for the purpose of transferring the results into the content of certain disciplines in the curriculum for environmental engineer must be signed.

\section{The New Content of Vocational Training of the Environmental Engineer}

Taking into consideration the above mentioned, we believe it is necessary to distinguish two main sections in the content of training of the environmental engineer:

1. The first section, where through a series of new didactic units (the names of which are derived from the names of the factors, features and components of the sixth technological paradigm, depending on the interests of the university, region, country), the place of natural resources in the nature and their significance for the living and inanimate nature, their classification, importance in human activities, and addressing global issues of natural resources, namely the depletion and pollution (i.e. deterioration), the causes of these problems (including the international division of labor), their main negative effects to animate and inanimate nature and man in the sixth technological paradigm are studied. The purpose of this section is a reflection of the situation that the depletion and pollution of natural resources will lead to some negative effects on other natural objects and 
human life itself, and understanding of the role and capabilities of the person in the deterioration of natural resources.

2. The second section, where through a series of other (new to the institution) subjects the ways to prevent the crisis of natural resources, referred to in general terms as the actual ecological basis of natural resources are suggested. The purpose of this section is to provide the students with environmental information on how to reduce the negative human impact on the planet's resources, affecting the human with political, legal, economic, technical and educational methods on a global scale. One of the most important areas covered in this section, should be the study of contemporary national and international innovative environmental engineering and environmental technologies of water purification, air, soil conservation and recycling, reduction of harmful impacts of energy and new technologies of energy and resources that especially important in the current economic crisis. It is necessary to pay special attention to the system of formation of the sixth technological paradigm in the economies of the world, since this technological system determines the future level of innovativeness and applicability of new environmentally-friendly technological and other solutions.

\section{Conclusion and Debate}

Thus, we propose to define a new direction of all branches of ecology, namely, focus on the study of aspects of the rational and economical use of natural resources with the use of appropriate innovative engineering and technological environmentally-friendly solutions and, through the "prism" of this study - to understand the causes, consequences and ways of preventing global crisis of resources on the planet. This process must necessarily take into account the new economic and technological conditions, defined as the process of global anthropogenic environmental impact and the possible technological approaches developed by clusters of the global economy within the framework of the upcoming sixth technological paradigm.

Based on the analysis it is possible to revise the content of the new environmental science on the new sixth stage of its development, corresponding to the sixth technological paradigm of the economy.

Earlier in the environmental science and pedagogy, as a rule, only the existence and interaction of organisms with each other and with inanimate nature, the negative impact of humans on the environment in terms of pollution and issues of a negative impact of environmental pollution on the existence and the interaction of living organisms and inanimate nature (for example, due to the increasing amount of acid rain destruction of vegetation, therefore, on this territory animals are going to die or migrate, etc.) were studied.

In the modern understanding of environmental science and pedagogy, in our opinion, such problems as the place of natural resources on the planet, their role on human and other natural objects, peculiarities of natural resources use by people, issues of irrational waste of resources and rationalizing of the use of resources in the light of their possible use for the implementation of new technologies of the sixth technological paradigm must be studied. There is a necessity to analyze new potential environmental problems associated with the possible acquiring of the negative and environmentally-unfriendly properties of new materials, as well as provision by the same technologies of the sixth technological paradigm with possibilities to preserve the environment.

In other words, the technology of the sixth technological paradigm when viewed from different above-mentioned sides must be studied in the various modules and the content of vocational training disciplines of the environmental engineer of the future.

\section{References}

Anciferova, A.A., Fridman V. (ed.) (2015). Nanotehnologii v povsednevnoy zhizni: gde taitsya opasnost [Nanotechnologies in everyday life: where danger is concealed?].V mire nauki, 3, 59-65.

Cawsey, D.C. (1996). Influencing the Future through Innovations in Environmental Engineering Education. European Journal of Engineering Education, 21, 4, 393-402.

Clancy, A.A., Gregoriou, Y., Yaehne, K., Cramb, D.T. (2010). Measuring properties of nanoparticles in embryonic blood vessels: Towards a physicochemical basis for nanotoxicity. Chemical Physics Letters, 488, 4-6, 99-111.

Didenko, M.M., Stezhka V.A. (2009). Vliyanie nanochastits amorfnogo vyisokodispersnogo kremnezema na morfologicheskuyu strukturu vnutrennih organov kryis [Effect of Nanoparticles of Amorphous Highly Dispersed $\mathrm{SIO}_{2}$ on Morphological Structure of the Rats' Inner Parts]. Biotehnologiya, 2, 1, 80-87.

Fogger, H., Mines, G. (1991). Technosphere: Open Researches. Vol. 1-2. Boston.

Glaszyev, S.Yu., Kharitonov, V.V. (eds.) (2009). Nanotehnologii kak klyuchevoy faktor novogo tehnologicheskogo uklada v ekonomike 
[Nanotechnologies as a Key Factor of New Technological Way in Economy]. Moscow: Trovant.

Knight, D.W. (1987). Dissemination of Information to Practicing Engineers and Researches in the Water Industry. Journal of the Institution of Water and Environmental Management. 1, 3, 315-324.

Nguyen, D.Q., Pudlowski, Z.J. (1999). Educating Engineers for the Environment: a Pilot Study on How Students Assess the Concept in Engineering Curricula. Global Journal of Engineering Education, 3, 2, 105-113.

Perez, C. (2002). Technological Revolutions and Financial Capital: The Dynamics of Bubbles and Golden Ages. London: Elgar.

Raysberg, B.A., Lozovskiy, L.Sh., Starodubtseva, E.B. (2007). Sovremennyiy ekonomicheskiy slovar [Modern economic dictionary] (5 ${ }^{\text {th }}$ ed.). Moscow: INFRA-M.

Schulenburg, M.; VDI Technologiezentrum GmbH, Dr. WS. Luther, Dr. G. Bachmann, Zukünftige Technologien Consulting (eds.); designe: S. Coppens. (2008). Nanochastitsyi - krohotnyie chastitsyi s ogromnyim potentsialom. Vozmozhnosti $i$ riski [Nanoparticles - tiny particles with a huge potential. Opportunities and risks]. Bonn-Berlin: Bundesministerium für Bildung und Forschung.

Semyonov, Yu.I. (2003). Proizvodstvo i obschestvo [Production and society]. In.: Gobozov I.A. (ed.) Sotsialnaya filosofiya. Kurs lektsiy. (str. 97-116). Moscow: Izdatel Savin S.A. 